\title{
Mantle cell lymphoma simulating inflammatory bowel disease
}

\author{
F. Lifrange ${ }^{1}$, R. de Wind ${ }^{1}$, C. Spilleboudt ${ }^{2}$ I. Karfis ${ }^{3}$, A. Van Gossum ${ }^{4}$, P. Demetter ${ }^{1}$ \\ Departments of (1) Pathology, (2) Haematology, (3) Nuclear Medecine, (4) Medical Oncology, Institut Jules Bordet, Université Libre de Bruxelles (ULB), Brussels, Belgium.
}

\begin{abstract}
We report a case of colorectal involvement by a mantle cell lymphoma (MCL) that had been considered before as inflammatory bowel disease. Diagnosis of low-grade MCL can be difficult, and here we highlight the importance of thorough histopathological examination in case of supposed inflammatory bowel disease that does not react to therapy. (Acta gastroenterol. belg., 2021, 84, 125127).
\end{abstract}

Keywords : inflammatory bowel disease, colorectal lymphoma, histopathology.

\section{Introduction}

Gastrointestinal (GI) lymphomas are rare and constitute $5 \%$ of all non-Hodgkin lymphomas. 10 to $20 \%$ of theses lymphomas are located in the colorectum. They represent $<0,1 \%$ of colorectal malignancies (1).

Colorectal lymphomas are usually diagnosed at an advanced stage and the prognosis is poor. Symptoms and endoscopic findings can be aspecific or suggest inflammatory bowel disease (IBD), rendering early diagnosis difficult and frequently leading to misdiagnosis.

\section{Case report}

A 72-year-old man, followed since many years for a thrombocytopenia of unknown origin, consulted a gastroenterologist after a positive faecal occult blood test. After questioning, the patient noticed watery stools two weeks prior to the consultation.

Clinical examination did not present any particularity. Biologic examination showed iron deficiency anaemia, known thrombocytopenia, normal liver and renal functions and discretely increased lactate dehydrogenase (LDH) and gamma globulin chain levels. Colonoscopy revealed an erythematous, friable, bleeding on contact mucosa in the rectum, the sigmoid, the left colon, the caecum, the ileocaecal valve and the terminal ileum (Fig. 1). Initial biopsies showed aspecific chronic inflammation. Since inflammatory bowel disease was suspected, budesonide and mesalazine treatment was immediately started.

At colonoscopy 6 weeks later, mucosa was still friable and bleeding on contact. Another set of biopsies was taken. Histopathological examination revealed a diffuse monotonous lymphocytic infiltrate (Fig. 2A). Numerous small lymphocytes expressed CD20, Bcl-2 and cyclin D1 (Fig. 2B-D) whereas immunohistochemical staining

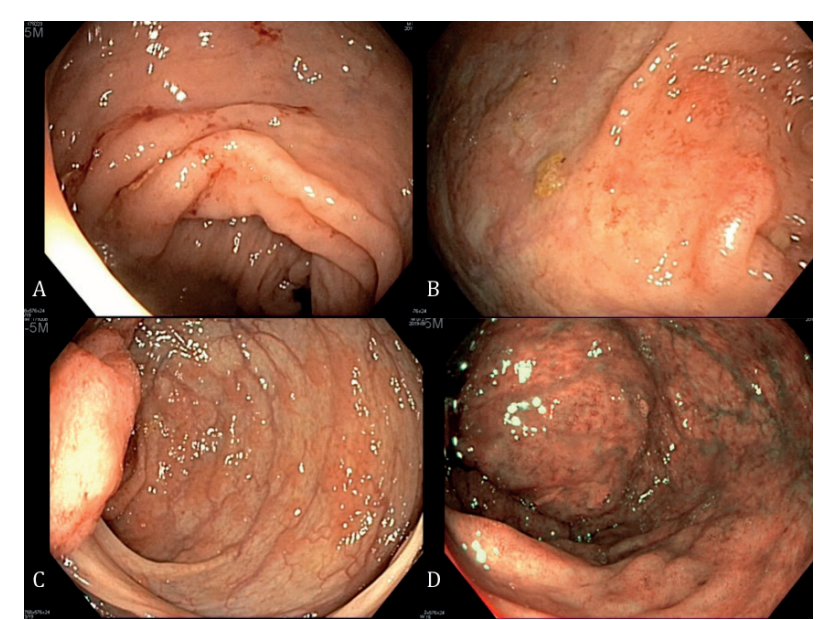

Figure 1. - Erythematous, friable, bleeding on contact mucosa observed at colonoscopy. (A) Left colon, (B) sigmoid, (C) caecum and (D) rectum.

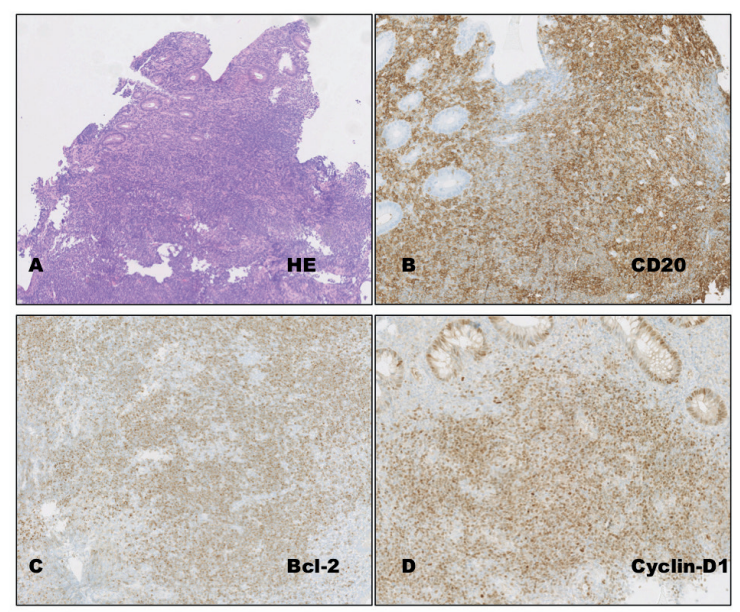

Figure 2. - (A) Diffuse monotonous lymphocytic infiltrate observed at haematoxylin-eosin (HE) staining. Lymphocytes were positive at immunohistological staining for (B) CD20, (C) Bcl-2 and (D) cyclin-D1.

for $\mathrm{CD} 5, \mathrm{CD} 10, \mathrm{CD} 23$ and Bcl-6 remained negative. Proliferation fraction was estimated $10-15 \%$ based on Ki-67 immunohistochemistry. A diagnosis of mantle cell lymphoma, classic variant was proposed.

Correspondence to : Pieter Demetter, Department of Pathology, Institut Jules Bordet, Héger-Bordet 1, B-1000 Bruxelles. Tel: +32 254136 98. Fax: +32 2 5413281.

E-mail : pieter.demetter@bordet.be

Submission date : 16/04/2020

Acceptance date : 13/05/2020 
${ }^{18}$ F-FDG PET/CT scan demonstrated multiple hypermetabolic supra- and infradiaphragmatic, cervical and mediastinal lymph nodes, splenomegaly, numerous hypermetabolic peritoneal foci and a diffuse radiotracer uptake throughout the colon wall. Bone marrow biopsy showed $15 \%$ involvement by neoplastic cells and allowed us to detect $\mathrm{t}(11 ; 14)(\mathrm{q} 13 ; \mathrm{q} 32)$, thereby confirming the diagnosis.

The patient is currently treated with rituximabbendamustine.

\section{Discussion}

The GI tract is a common site of presentation for extranodal lymhomas. A broad range of lymphoproliferative disorders occur in the GI tract and, with only few exceptions, most of these exhibit features similar to those encountered in their nodal or other extranodal sites $(1,2-5)$.

MCL is a rare non-Hodgkin lymphoma with an annual incidence of $1-2$ cases per 100.000 people. It represents $6-9 \%$ of all lymphomas. MCL is incurable, with often an advanced stage at diagnosis and a poor prognosis. This type of lymphoma has a male predominance with a median age of diagnosis at the sixth decade of life (6).

MCL can be easy to diagnose in case of clinical suspicion and when typical morphology and typical immunophenotype are combined. In the great majority of cases, immunohistochemistry for $\mathrm{T}$ cell related antigen CD5 is positive ; in a series of 112 cases of MCL, 8 cases where, however, negative just as the present case (6).

MCL is characterised in $95 \%$ of cases by $\mathrm{t}(11 ; 14)$ (q13;q32), juxtaposing the CCND1 gene with $\operatorname{IgH}$ on the derivative chromosome 14 resulting in cyclin D1 overexpression and dysregulation of the cell cycle. However, overexpression of cyclin D1 alone is insufficient to induce malignant transformation. Secondary genetic alterations and deregulated signaling pathways involved in DNA damage response, cell proliferation and apoptosis are also indispensable for MCL lymphomagenesis (7).

The classic variant of MCL is composed of mature B cells that do not enter the germinal centre, have no or minimal mutations in $I G H V$ and express the transcription factor SOX11 (8). The primary site of appearance is a lymph node in $75 \%$ of cases. It spreads usually in first intention to the blood, the spleen and the bone marrow. The remaining $25 \%$ occur at other sites, including the GI tract. However, when it occurs in this tract, the stomach is the most frequently involved site, followed by the small bowel and finally the colorectum, with predominance in this latter for the ileocaecal region (9).

The Dawnson criteria for determination of primary colorectal lymphoma include 5 items : 1) no enlarged superficial lymph nodes, 2) chest radiograph with no mediastinal node enlargement, 3) normal white blood cell count and normal bone marrow biopsy, 4) only regional nodal disease at surgery, and 5) no liver or spleen involvement (1).
MCL can present with a characteristic endoscopic image when it involves the colon, known as multiple lymphomatous polyposis, described as a large segment of colon covered by a lot of small polyps (10). Nevertheless, this image is variable and usually symptoms are unspecific: abdominal pain, melena, bloody stools, diarrhoea and/or epigastric pain. At endoscopy diagnosis can be easier if the involvement appears as a bulky mass. More often, however, the mucosa is normal or oedematous and, comforted by the clinic, it can mimic an IBD. Moreover, biopsies can appear normal at first sight if a lymphoma is not suspected. In consequence, studies have shown that in a quarter of cases of MCL, there is a macroscopic involvement of the colon and in $84 \%$ of cases, there is a microscopic involvement of macroscopically normal appearing mucosa (9).

IBD includes Crohn's disease (CD), UC and IBDunclassified when the differential diagnosis remains unclear after surgery and histopathological examination of the surgical specimen. MCL is able to mimic IBD and few such cases have been reported so far (11-14). A study comparing $\mathrm{CD}$ with primary lymphomas of the colon did not reveal significant differences with regard to sex, weight and height. The CD patients were, however, significantly younger than the lymphoma patients in terms of age of onset $(32.0+/-9.9$ years vs $52.8+/-16.3$ years). Concerning symptoms, there was no significant difference with regard to nausea, vomiting, fever, weight loss and pain. Diarrhoea was more frequent, in terms of incidence, frequency and volume, in $\mathrm{CD}$ than in colonic lymphoma. At endoscopy, ulcers from lymphoma were more irregular. The incidence of abdominal masses was higher in lymphoma. Laboratory data showed that increased lactate dehydrogenase and beta-globulin levels were in favour of a lymphoma (15).

A single center study showed that in patients with known MCL there is no clinical impact of GI involvement on the clinical course and no GI complications occurred during chemotherapy, arguing against a routine GI assessment in patients diagnosed with MCL (16).

There is no commonly accepted standard therapy for MCL. Chemotherapy is most frequently used and depends on the MCL International Prognostic index (MIPI). For younger patients $(<65$ years old $)$ with intermediate or high risk MIPI, rituximab-cytarabine followed by autologous stem cell transplantation is the first choice. For asymptomatic patients or older patients with a low MIPI, a « watch and wait » strategy can be considered. For older symptomatic patients with indermediate or high risk MIPI, combination chemotherapy with rituximabCHOP, rituximab-bendamustine or a possible inclusion in a clinical trial should be considered (17). Surgery may have a place in case the GI involvement is symptomatic with risk of obstruction or perforation.

In conclusion, MCL is a rare and aggressive lymphoma that can, like some other types of lymphomas, involve the GI tract. When occurring in the colorectum, clinical signs can mimic an IBD. Histological examination is of 
utmost importance but diagnosis can be difficult in case of lack of clinical suspicion.

\section{Conflicts of interest and source of funding}

None declared.

\section{References}

1. SKUBE S.J., ARSONIADIS E.G., SULCINER M.L., GILLES S.R., GAERTNER W.B., MADOFF R.D., et al. Colorectal Lymphoma : A Contemporary Case Series. Dis. Colon Rectum, 2019, 62 : 694-702.

2. GOU H.F., ZANG J., JIANG M., YANG Y., CAO D., CHEN X.C. Clinical prognostic analysis of 116 patients with primary intestinal non-Hodgkin lymphoma. Med. Oncol., 2012, $29: 227-234$

3. O'MALLEY D.P., GOLDSTEIN N.S., BANKS P.M. The recognition and classification of lymphoproliferative disorders of the gut. Hum. Pathol., 2014, 45 : 899-916.

4. DEMEESTER P., DEWINT P., SCHAUVLIEGE L., GABRIEL C., VAN MOERKERCKE W. Capsule endoscopy : diagnosis of intestinal localisation of systemic follicular B-cell non-Hodgkin lymphoma. Acta Gastroenterol. Belg., 2020, $83: 73-75$

5. CHUAH Y.Y., TASHI T., LEE Y.Y., FU T.Y., SHIH C.A. Enteropathyassociated T-cell Lymphoma (EATL) with intracranial metastasis : a rare and dismal condition. Acta Gastroenterol. Belg., 2020, 83 : 77-80.

6. ZHOU D.M., CHEN G., ZHENG X.W., ZHU W.F., CHEN B.Z. Clinicopathological features of 112 case with mantle cell lymphoma. Cancer Biol. Med., 2015, $12:$ 46-52.

7. VOGT N., DAI B., ERDMANN T., BERDEL W.E., LENZ G. The molecular pathogenesis of mantle cell lymphoma. Leuk. Lymphoma, 2017, 58 : 15301537.
8. MADDOCKS K. Update on Mantle Cell Lymphoma. Blood, 2018, 132 : $1647-1656$.

9. AHMED R., KUMAR K., MAKKER J., NIAZI M., BALAR B. Recurrent Mantle Cell Lymphoma Presenting as Gastrointestinal Bleeding. Case Rep. Gastroenterol., 2018, 12 :379-384.

10. SCIAUdONE G., PELlinO G., SElVAGgi F. Diagnostic pitfalls : Cancerization in IBD versus mantle cell lymphoma presenting with multiple lymphomatous polyposis. Inflamm. Bowel Dis., 2011, 17 : E28-E30.

11. McCULlOUGH J.E., KIM C.H., BANKS P.M. Mantle cell lymphoma of the colon simulating diffuse inflammatory bowel disease. Role of immunohistochemistry in establishing the diagnosis. Dig. Dis. Sci., 1992, 37 : 934938.

12. ROBERT M.E., KUO F.C., LONGTINE J.A., SKLAR J.L., SCHROCK T., WEIDNER N. Diffuse colonic mantle cell lymphoma in a patient with presumed ulcerative colitis : detection of a precursor monoclonal lymphoid population using polymerase chain reaction and immunohistochemistry. $A m$. J. Surg. Pathol., 1996, 20 : 1024-1031.

13. HURLSTONE D.P. Early phase mantle cell lymphoma: macroscopic similarities to terminal ileal Crohn's disease. Am. J. Gastroenterol., 2002, $97: 1577-1578$.

14. KOKSAL A.S., TASKIRAN I., KALKAN I.H., KAYACETIN E. A rare endoscopic appearance of primary gastrointestinal mantle cell lymphoma resembling ulcerative colitis. Bratisl. Lek. Listy, 2014, 115 : 800-801.

15. ZHANG T.Y., LIN Y., FAN R., HU S.R., CHENG M.M., ZHANG M.C., et al. Potential model for differential diagnosis between Crohn's disease and primary intestinal lymphoma. World J. Gastroenterol., 2016, 22 : 9411-9418.

16. LAMM W., DOLAK W., KIESEWETTER B., SIMONITSCH-KLUPP I., PUHR H., RADERER M. Gastrointestinal Involvement in Patients with Mantle Cell Lymphoma : A Single Center Experience of Eighty-Five Patients. Dig. Dis., 2019, 37 : 194-200.

17. VOSE J.M. Mantle cell lymphoma: 2017 update on diagnosis, riskstratification, and clinical management. Am. J. Hematol., 2017, 92 : 806-813. 